\title{
Input from the medial geniculate nucleus modulates amygdala encoding of fear memory discrimination
}

\author{
Nicole C. Ferrara, Patrick K. Cullen, Shane P. Pullins, Elena K. Rotondo, \\ and Fred J. Helmstetter \\ Department of Psychology, University of Wisconsin-Milwaukee, Milwaukee, Wisconsin 53211, USA
}

\begin{abstract}
Generalization of fear can involve abnormal responding to cues that signal safety and is common in people diagnosed with post-traumatic stress disorder. Differential auditory fear conditioning can be used as a tool to measure changes in fear discrimination and generalization. Most prior work in this area has focused on elevated amygdala activity as a critical component underlying generalization. The amygdala receives input from auditory cortex as well as the medial geniculate nucleus $(\mathrm{MgN})$ of the thalamus, and these synapses undergo plastic changes in response to fear conditioning and are major contributors to the formation of memory related to both safe and threatening cues. The requirement for MgN protein synthesis during auditory discrimination and generalization, as well as the role of $\mathrm{MgN}$ plasticity in amygdala encoding of discrimination or generalization, have not been directly tested. GluR1 and GluR2 containing AMPA receptors are found at synapses throughout the amygdala and their expression is persistently up-regulated after learning. Some of these receptors are postsynaptic to terminals from $\mathrm{MgN}$ neurons. We found that protein synthesis-dependent plasticity in $\mathrm{MgN}$ is necessary for elevated freezing to both aversive and safe auditory cues, and that this is accompanied by changes in the expressions of AMPA receptor and synaptic scaffolding proteins (e.g., SHANK) at amygdala synapses. This work contributes to understanding the neural mechanisms underlying increased fear to safety signals after stress.
\end{abstract}

Dysregulation of fear responses is commonly seen in individuals diagnosed with post-traumatic stress disorder (PTSD) (Norrholm et al. 2011). Differential fear conditioning provides a model to measure learned fear responses, as well as the factors contributing to the generalization of fear (Antunes and Moita 2010; Ghosh and Chattarji 2015). During training, a neutral auditory conditional stimulus (CS+) is paired with an aversive outcome such as a footshock, while a different auditory stimulus (CS-) is never paired with shock. This results in the behavioral expression of a precise fear memory, more specifically defined as a high degree of responding to the CS+ and a low degree of responding to the CS-. However, under certain circumstances, animals will generalize fear between the CS+ and CS-, exhibiting equivalent levels of behavioral performance to both cues similar to maladaptive fear responses seen in individuals suffering from PTSD (Jovanovic et al. 2012).

The discrimination of auditory cues may depend on auditory thalamic and cortical inputs to the amygdala. Synaptic connections from the auditory cortex (ACX) and medial geniculate nucleus $(\mathrm{MgN})$ within the amygdala undergo plastic changes in response to fear conditioning and require de novo protein synthesis for successful memory consolidation, suggesting that protein synthesisdependent plasticity throughout the neural circuit is critical for encoding of auditory fear (Kraus et al. 2002; Parsons et al. 2006a,b; Shaban et al. 2006; Helmstetter et al. 2008; Ghosh and Chattarji 2015). Activity in the MgN and ACx is critical for the formation of memories for both auditory signals for shock and safety, and thalamic and cortical presynaptic activity in the amygdala modulates the degree of fear generalization across auditory cues. Specifically, a lack of presynaptic inhibition may be associated with high fear generalization (Kraus et al. 2002; Shaban et al. 2006). Recent work illustrates that ACx activity may not be the

\section{Corresponding author:fjh@uwm.edu}

Article is online at http://www.learnmem.org/cgi/doi/10.1101//m.044131.116. primary factor underlying elevated responding to safety cues (Ghosh and Chattarji 2015). The MgN has been implicated in the encoding of differential fear memory and generalization of auditory cues (Han et al. 2008; Antunes and Moita 2010). Specifically, $\mathrm{MgN}$ protein synthesis-dependent plasticity as well as normal activity of terminals in the amygdala is critical for auditory fear consolidation, suggesting that $\mathrm{MgN}$ activity may modulate fear generalization by presynaptically modulating amygdala encoding of fear (Parsons et al. 2006a; Shaban et al. 2006; Han et al. 2008; Kwon et al. 2014).

Potentiation of glutamatergic amygdala synapses is thought to be a critical factor underlying fear memory formation. Several studies have shown that memory consolidation and maintenance are characterized by increased synaptic expression of GluR1 and GluR2 AMPA receptor subunits at synapses in the amygdala following conditioning (Yeh et al. 2006; Migues et al. 2010; Thoeringer et al. 2012). For example, increased amygdala GluR1 expression is maintained in the synapse for up to $24 \mathrm{~h}$ following conditioning (Yeh et al. 2006), and the loss of GluR1 subunit expression disrupts LTP at thalamic inputs to the lateral amygdala as well as memory formation, collectively suggesting that maintaining AMPA receptor synaptic expression is a mechanism supporting long-term memory formation (Schmitt et al. 2003; Humeau et al. 2007). Some of these amygdala GluR1 and GluR2 containing AMPA receptors are immediately postsynaptic to $\mathrm{MgN}$ terminals and are persistently up-regulated at the synapse surface for extended durations, suggesting direct influence of MgN activity on stable molecular

\footnotetext{
(C) 2017 Ferrara et al. This article is distributed exclusively by Cold Spring Harbor Laboratory Press for the first 12 months after the full-issue publication date (see http://learnmem.cshlp.org/site/misc/terms.xhtml). After 12 months, it is available under a Creative Commons License (Attribution-NonCommercial 4.0 International), as described at http://creativecommons.org/licenses/ by-nc/4.0/.
} 
processes critical for auditory fear memory formation (Farb and LeDoux 1997; Yeh et al. 2006; Radley et al. 2007). Therefore, the synaptic expression of AMPA receptors provides an indirect way to measure the contribution of $\mathrm{MgN}$ plasticity in the amygdala during memory formation.

In the following experiments we address the role of the $\mathrm{MgN}$ in differential fear conditioning during high and low states of generalization as well as how the $\mathrm{MgN}$ modulates amygdala synaptic plasticity underlying low and high levels of generalization. We show that protein synthesis in the $\mathrm{MgN}$ is necessary for auditory fear memory formation during successful discrimination. During a second training session, we increased the intensity of shocks delivered following the CS+ resulting in elevated CS-, and maintained $\mathrm{CS}+$, freezing. To determine the role of protein synthesis in the $\mathrm{MgN}$ during states of high fear generalization, we injected anisomycin bilaterally into the $\mathrm{MgN}$ prior to the second training session at a recent or remote time point to test the temporal requirement of plasticity in the $\mathrm{MgN}$ during the second training session. We found that $\mathrm{MgN}$ protein synthesis during the second training session is critical for the increase in CS- responding and prevents the increased synaptic expression of GluR1 containing AMPA receptor subunits and postsynaptic scaffolding at amygdala synapses that may underlie generalization of fear.

\section{Results}

\section{$\mathrm{MgN}$ protein synthesis contributes to differential fear memory formation}

Fear memory formation is dependent on de novo protein synthesis in several brain structures (for review, see Helmstetter et al. 2008). Previous work has demonstrated that $\mathrm{MgN}$ protein synthesisdependent plasticity is critical for the consolidation of an auditory fear memory with a single CS (Apergis-Schoute et al. 2005; Parsons et al. 2006a; but see Maren et al. 2003), while lesion work also suggests a role for the $\mathrm{MgN}$ in differential (CS+/CS-) auditory fear memory formation (Antunes and Moita 2010). We first microinfused anisomycin into the $\mathrm{MgN}$ prior to differential fear conditioning to determine whether protein synthesis-dependent plasticity is necessary during the formation of differential auditory fear memory (Fig. 1A). There were no significant differences in behavior between vehicle and drug infused groups during fear training $\left(F_{(2,36)}\right.$ $=0.5607, P=0.5757$, Fig. $1 \mathrm{~B})$. To test long-term retention of the fear memory, animals received a CS retrieval session in a shifted context $24 \mathrm{~h}$ after training. There was a significant main effect for freezing responses to CS $\left(F_{(1,15)}=35.74, P<0.0001\right)$ as well as a statistically marginal CS $\times$ Drug interaction $\left(F_{(2,28)}=2.758, P=\right.$
0.080). Fisher's LSD post hoc revealed a significant difference within CS+ freezing between vehicle and anisomycin drug groups $(P<$ $0.05)$ but not freezing behavior during the CS $-(P=0.9229)$ (Fig. $1 C)$. This result demonstrates that protein synthesis inhibition in the $\mathrm{MgN}$ prior to training disrupts memory for the CS+ when vehicle infused animals show minimal amounts of generalization.

\section{$\mathrm{MgN}$ protein synthesis is necessary for the shift from low to high generalization}

Amygdala neurons preferentially respond to shock associated auditory cues during fear memory formation (Goosens et al. 2003). During fear discrimination, neuronal responses in the amygdala are highest to the CS+ and low to the CS-, and as fear to the CSincreases, a higher population of amygdala neurons responds to both CS+ and CS- cues (Ghosh and Chattarji 2015). This transition in neuronal responding is independent of auditory cortex activity, suggesting a direct relationship between behavioral expression of fear and cellular responding to auditory cues in the amygdala that could be regulated by auditory thalamic input. We wanted to determine whether the $\mathrm{MgN}$ is necessary for shifting fear responding to $\mathrm{CS}$ - cues from low to high states of generalization. Low intensity footshocks $(0.5 \mathrm{~mA})$ were paired with the CS+ during the first training session, and stronger footshocks (1.0 mA) were paired with the CS+ during the second training session to determine whether protein synthesis in the $\mathrm{MgN}$ is critical for the change from low to high generalization (Fig. 2A). Prior to the initial training session, all animals were infused with vehicle and tested $24 \mathrm{~h}$ later to ensure groups showed equal discrimination performance (Fig. 2B). During a second training session with strong shock, we found a main effect for drug $\left(F_{(1,15)}=7.991, P<0.05\right)$, and CS $\left(F_{(2,30)}=109.7, P<0.0001\right)$, as well as a CS $\times$ Drug interaction $\left(F_{(2,30)}=5.240, P<0.05\right)$. Vehicle infused animals showed elevated responding to both $C_{+}+(P<0.01)$ and $C S-(P<0.01)$ cues compared with $\mathrm{MgN}$ anisomysin-treated animals (Fig. 2C). To normalize performance and compare freezing within each animal following the first and second training session, freezing responses to each CS+ and CS- presentation during both tests were divided to create a change score (see Materials and Methods). Using the change score, we found a significant main effect for $\operatorname{drug}\left(F_{(1,15)}=6.786\right.$, $P<0.05), C S\left(F_{(1,15)}=8.242, P<0.05\right)$, and a significant $C S \times$ Drug interaction $\left(F_{(1,15)}=5.763, P<0.05\right)$. The second training session increased the amount of responding to the CS- between tests when infused with vehicle but not anisomycin $(P<0.01)$, suggesting that the strongest change in responding between training sessions as a result of increased shock intensity is to the CS- despite the significant increase in freezing to the CS+ at the second test

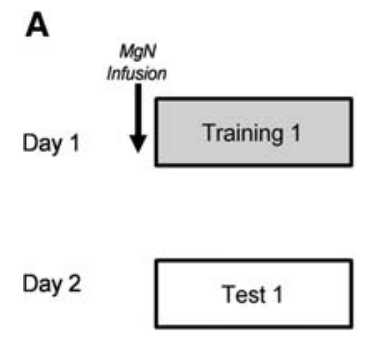

B
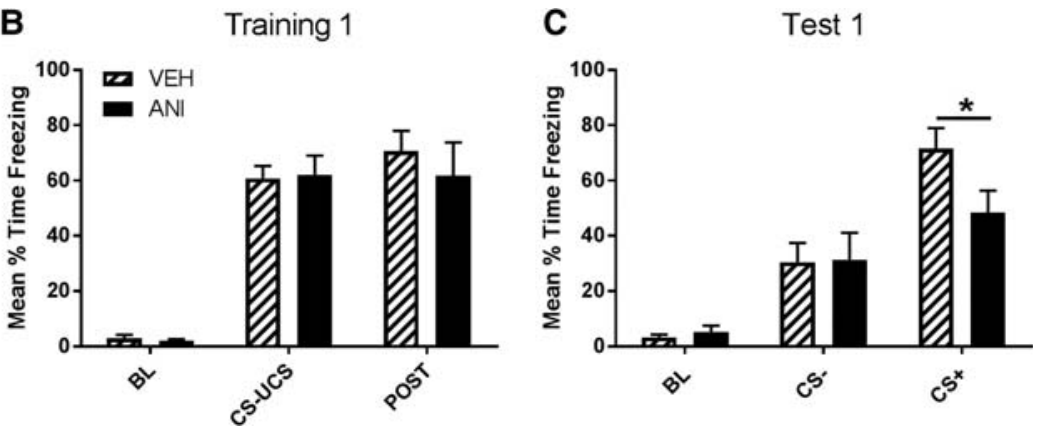

Figure 1. MgN protein synthesis contributes to differential fear memory formation. (A) Rats were infused with anisomysin or vehicle (ACSF) 30 min before differential fear conditioning using random presentations of CS+-UCS and CS- cues and a $0.5 \mathrm{~mA}$ footshock $(n=7-9)$. Groups were tested for their memory to unreinforced CS+ and CS- cues 24-h following training. (B) There were no differences between groups during training. (C) Animals that received anisomycin infusions prior to training showed significantly less freezing to the CS+ when tested 24-h later during the 30-sec tone presentations. $\left({ }^{*}\right) P<0.05$. 

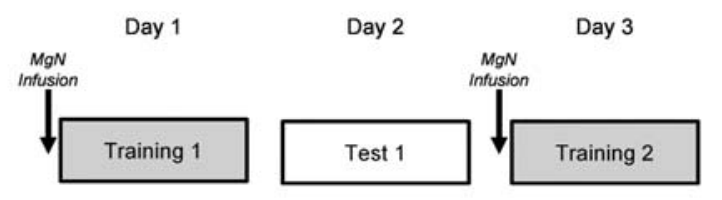

B

C

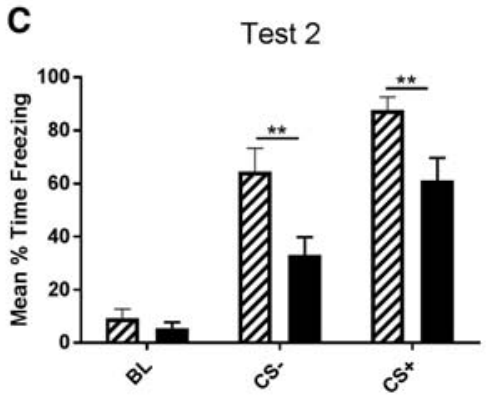

D Cs Change Score

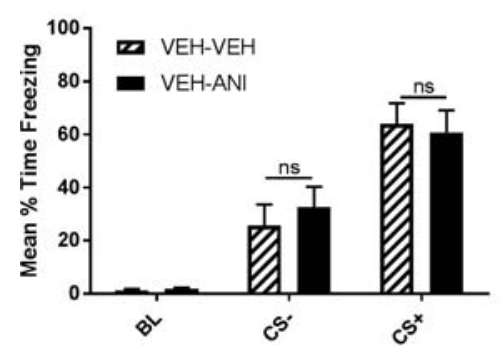

E

Day 1

Day 2

Day 14

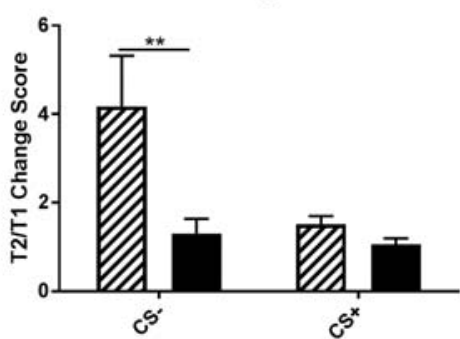

Day 15
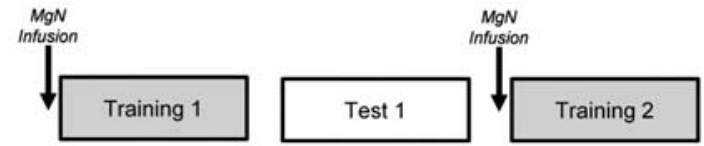

Test 2

F

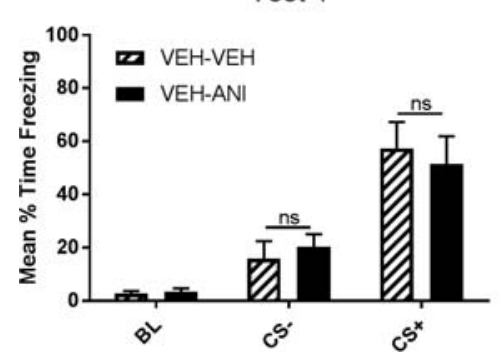

G

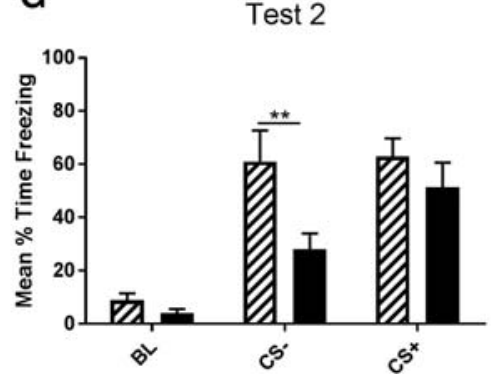

H

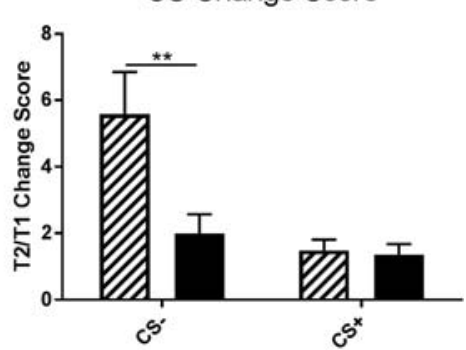

Figure 2. MgN protein synthesis is necessary for the shift from low to high generalization. (A) Rats were infused with vehicle (ACSF) 30-min before the first training session using a $0.5 \mathrm{~mA}$ footshock followed by a test $24-\mathrm{h}$ after training. Rats received a second infusion of either vehicle or anisomycin 30-min prior to the second training session using a $1.0 \mathrm{~mA}$ footshock followed by a long-term retention test 24-h later $(n=8-9)$. (B) There were no differences between groups during the 30-sec tone presentations at the discrimination test. (C) Animals that received anisomycin infusions prior to the second training session showed significantly less freezing during the CS+ and CS- presentations when tested 24-h later. $(D)$ Animals that received vehicle infusions showed increased freezing during the CS- between the discrimination and generalization test in comparison to anisomycin infused animals. $(E)$ Procedures were identical to $A-D$ with the exception that the first test and second training session are separated by $12 \mathrm{~d}$. ( $F$ ) Groups were not significantly different during the 30-sec tone presentations at the discrimination test. $(G)$ Animals that received vehicle infusions showed increased freezing during the CS- presentations in comparison to animals that received anisomycin infusions. $(H)$ Animals that received vehicle infusions showed increased freezing during the CSbetween the discrimination and generalization test in comparison to anisomycin infused groups. $\left(^{*}\right) P<0.05$.

(Fig. 2D). Furthermore, this shift in fear expression in response to the second training session is dependent on protein synthesis in the MgN during memory encoding and/or consolidation.

The neural circuitry necessary to support a fear memory can change with time (Frankland et al. 2004; Maviel et al. 2004; Do-Monte et al. 2015). Previous work has reported changes in neural circuits supporting a memory as early as $7 \mathrm{~d}$ (Do-Monte et al. 2015). To test the stability of the changes resulting from the second training session, we separated the first test session and the second training session by $12 \mathrm{~d}$ (Fig. 2E). During the second test, we found a significant main effect for CS $\left(F_{(2,32)}=41.05, P<0.0001\right)$, and drug $\left(F_{(1,16)}=4.569, P<0.05\right)$, in addition to a nearly significant $\mathrm{CS} \times$ Drug interaction $\left(F_{(2,32)}=3.210, P=0.0537\right)$. Similar to the recent second training session, the delayed second training session using an increased shock intensity resulted in elevated CS- responding that was prevented with anisomycin infusions into the $\mathrm{MgN}(P<0.01$, Fig. $2 \mathrm{G})$. The CS change score revealed a significant main effect for CS $\left(F_{(1,16)}=9.874, P<0.01\right)$, drug $\left(F_{(1,16)}=6.872, P\right.$ $<0.05)$, and a significant CS $\times$ Drug interaction $\left(F_{(1,16)}=5.275, P<\right.$
0.05). The change in responding to cues due to the second training was most evident in CS- presentations and was prevented with $\mathrm{MgN}$ protein synthesis inhibition $(P<0.01$, Fig. $2 \mathrm{H})$, suggesting that persistent $\mathrm{MgN}$ protein synthesis-dependent plasticity is critical for the change in fear responding from low to high generalization of fear.

\section{$\mathrm{MgN}$ protein synthesis is critical for changes in amygdala AMPA receptors}

The amygdala is a critical site for plasticity during fear memory formation and is known to be necessary for both initial fear memory formation and post-retrieval modification (Gale et al. 2004; Tronson et al. 2006; Pedroso et al. 2013). Much of the fear generalization literature has focused on changes in amygdala activity, but mechanisms through which the MgN modulates synaptic activity in the amygdala necessary for auditory memory formation and updating remain unclear. The goal of this experiment was to determine how protein synthesis-dependent processes in the $\mathrm{MgN}$ 
modulate amygdala activity necessary to support transitions in low to high generalized responding. Animals were implanted with cannula targeting the $\mathrm{MgN}$ and were infused with vehicle prior to the initial training session, known to result in discrimination between cues, and infused with anisomysin or vehicle 30-min prior to the second training session (Fig. 3A). Animals were sacrificed 30 or 90 min after the second training session and crude synaptosomal fractions from amygdala tissue were obtained. Groups that did not receive a second training session were infused with vehicle and returned to their home cages for the duration of the second training session and sacrificed at a 90 min time point. We measured changes in GluR1 and GluR2 containing AMPA receptors and synaptic scaffolding proteins such as SHANK and PSD95. Both PSD95 and SHANK are stable synaptic scaffolds that can be regulated in response to behavioral experience. Specifically, increases in PSD95 have been correlated with the formation of new synaptic connections while changes in SHANK regulate AMPA receptor stability in the PSD. We found $\mathrm{MgN}$ protein synthesis disruption prevented amygdala changes in SHANK and AMPA receptor synaptic expression in response to the second training session. The second training session caused increases in amygdala GluR1 synaptic expression $\left(F_{(4,33)}=4.943, P<0.05\right)$, which was prevented when protein synthesis was inhibited in the $\operatorname{MgN}(P<0.001$, Fig. 3B). Similar to GluR1 patterns, SHANK was increased following the second training session $\left(F_{(4,33)}=3.039, P<0.05 ; 30 \mathrm{~min} P<0.01\right)$ with modest reductions in anisomycin infused groups (Fig. 3D). There were no increases in GluR2 expression as a factor of training; however, there was a significant decrease in GluR2 synaptic expression in the group that was infused with anisomycin $\left(F_{(4,31)}=4.277, P<\right.$ 0.01 , Fig. $3 \mathrm{C}$ ). These results suggest that generalization as a result of elevated shock intensity during the second training session are dependent on increases in GluR1 synaptic expression and SHANK levels in amygdala synapses. We were also interested in potential changes in the stability and function of synaptic connections as a result of the second training session. To address this, we measured levels of synaptophysin and PSD95 and found that these synaptic proteins did not change as a factor of training or drug infusion (Fig. $3 \mathrm{E}, \mathrm{F})$. These results suggest that behavioral changes as a result of the second training session are accompanied by synaptic modifications in the amygdala at sites that originally engaged in fear memory formation from the initial training session.

\section{Discussion}

We provide new data showing MgN protein synthesis-dependent plasticity contributes to the formation of auditory fear memory and the elevation of fear to safety cues under stressful conditions that promote generalized responding. We found that increases in UCS intensity during a second training session resulted in

A

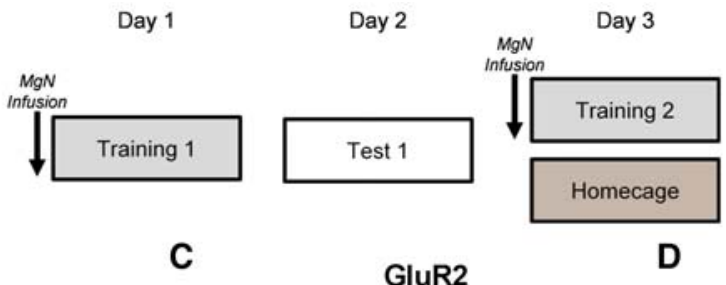

B

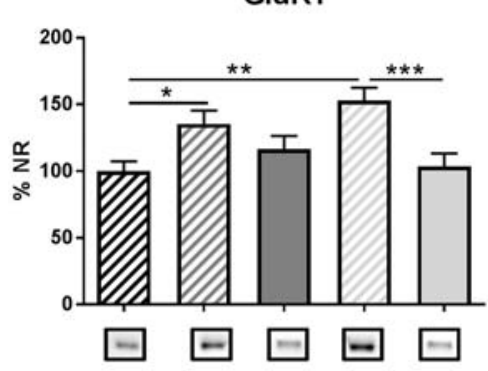

E

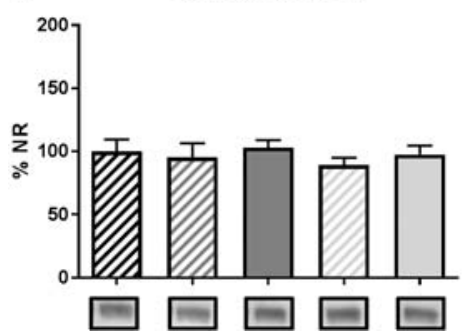

C

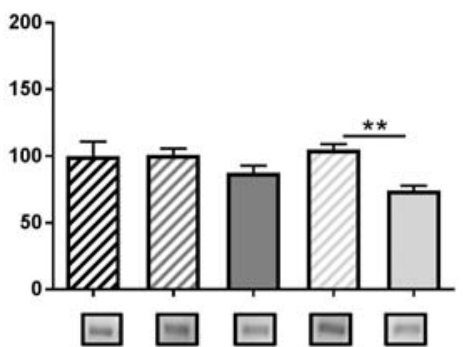

D

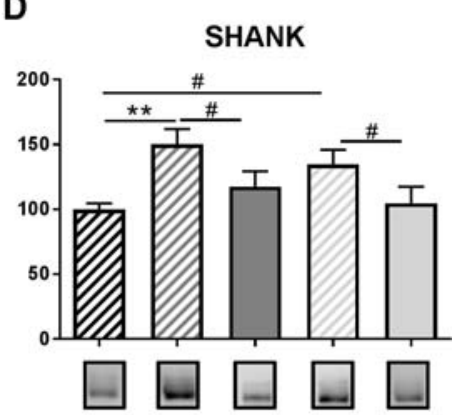

$\mathbf{F}$

PSD95

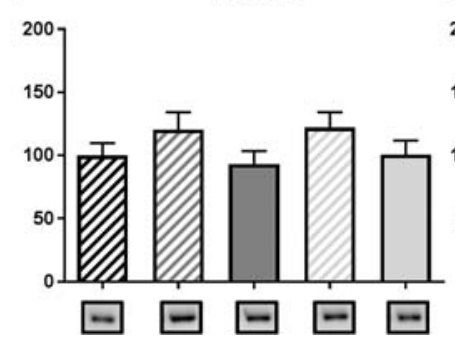

Actin

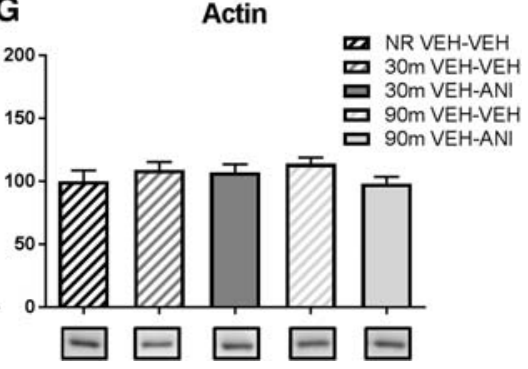

Figure 3. MgN protein synthesis is critical for changes in amygdala synaptic expression of AMPA receptors underlying the change from low to high fear generalization. (A) Rats were infused with vehicle (ACSF) 30-min before the first training session using random presentations of CS+-UCS and CS- cues using a $0.5 \mathrm{~mA}$ footshock followed by a test 24-h after the first training session. Rats received a second infusion of either vehicle or anisomycin 30-min prior to the second training session using a $1.0 \mathrm{~mA}$ footshock and were sacrificed 30 or $90 \mathrm{~min}$ following training. Animals that did not receive a second training session were infused with vehicle and placed back into their homecages for the duration of the training session and were sacrificed 90-min later $(n=6-9)$. $(B, D)$ The second training session is characterized by increased amygdala GluR1 and SHANK synaptic expression that is prevented with infusion of anisomycin into the $\mathrm{MgN}$. (C) Anisomycin infusions into the $\mathrm{MgN}$ reduced the amount of GluR2 in synaptosomal fractions. (E-G) Expression of synaptophysin, PSD95, and $\beta$-actin were not changed due to training or drug infusion. (\#) $\left.P<0.07,\left({ }^{\star}\right) P<0.05,{ }^{* *}\right) P<0.01,\left({ }^{* * *}\right) P<0.001$. 
heightened fear to CS+ and CS- cues, and the change in fear expression as a result of the second training session was most evident in response to CS- cues. The heightened fear responding to safety cues is also a characteristic of individuals suffering from PTSD (Jovanovic et al. 2012), suggesting that understanding the process underlying shifts from low to high generalization may contribute to a better understanding of fear related disorders. Furthermore, we found protein synthesis in the $\mathrm{MgN}$ is necessary for the increase in CS- freezing following a second training session, which would typically result in generalization of fear. These data highlight the importance of shock intensity during training and the neural circuit modulating amygdala-dependent memory storage in generalization of fear.

The amygdala is a major locus of plasticity for fear memory formation and updating, and a majority of the work on fear generalization has centered on amygdala activity (Shaban et al. 2006; Likhtik et al. 2014; Ghosh and Chattarji 2015). Specifically, reductions in presynaptic inhibition in the amygdala may contribute to an imbalance between excitatory and inhibitory processes underlying transitions in cue specific responding and generalized fear (Shaban et al. 2006; Bergado-Acosta et al. 2008; Likhtik et al. 2014; Ghosh and Chattarji 2015). A lack of presynaptic inhibition or facilitation of PKA signaling in the amygdala produces generalized fear responding during memory formation (Shaban et al. 2006; Ghosh and Chattarji 2015). The amygdala receives information from the $\mathrm{MgN}$ and $\mathrm{ACx}$ during auditory fear conditioning which may contribute to the formation of cue specific amygdala cells during auditory memory formation. Inhibition of MgN protein synthesis prior to differential fear conditioning using a 0.5 $\mathrm{mA}$ footshock reduces the amount of time spent freezing to the CS+ in comparison to vehicle infused groups, suggesting that protein synthesis-dependent plasticity is critical for the formation of a relatively precise fear memory. These findings are consistent with previous work showing that inhibition of $\mathrm{MgN}$ protein synthesis or blocking phosphorylation of ERK/MAPK during auditory fear conditioning results in lower fear to an auditory cue the following day in comparison to control groups (Apergis-Schoute et al. 2005; Parsons et al. 2006a). While we, and others, found that plasticity in the $\mathrm{MgN}$ prior to auditory conditioning disrupts auditory fear memory formation, others have shown that increasing CREB activity in the $\mathrm{MgN}$ prior to fear conditioning can result in generalized fear to multiple tones, suggesting that the current state of $\mathrm{MgN}$ plasticity during training may be critical (Han et al. 2008). $\mathrm{MgN}$-dependent plasticity may play a role in the increased responding to safety signals after training with increased shock.

To elevate CS- responding we increased the shock intensity paired with the CS+ during a second training session. We found that protein synthesis in the $\mathrm{MgN}$ is necessary during the second training session for the change in fear responding to the CS- measured in a separate test session without shock. While we also saw increases in fear responding to the CS+ with elevated shock intensity at a recent time point, we would like to highlight that the largest change in responding at both recent and remote time points was to the CS-. Human work has shown that impaired safety learning or fear inhibition is a good index of fear generalization in PTSD patients (Jovanovic and Ressler 2010; Jovanovic et al. 2010, 2012). Therefore, this model may provide a useful tool for describing the molecular mechanisms underlying changes in fear to safety cues. Previous rodent work also shows behavioral variability in the degree of discrimination, which may involve equivalent CS+/CS - fear or elevated fear to safe or neutral cues that may still be lower than the paired cue or context (Gafford et al. 2013; Xu and Südhof 2013; Cullen et al. 2015; Ghosh and Chattarji 2015; Sanford et al. 2017; Vanvossen et al. 2017). While our results are consistent with behavioral models of generalization, nonassociative factors (e.g., sensitization; Groves and Thompson 1970) could be contributing to elevated fear between test days. We are not able to control for all possible alternative interpretations with our current design. However, our baseline fear prior to discrete cue presentation between test days is relatively low, suggesting that fear is limited to discrete cues and not expressed to the shifted context or all nonassociated cues. The baseline levels of fear in combination with previous literature supporting our approach argue that we are measuring generalization of associative responses.

Previous work has shown that changes in the neural circuitry supporting a fear memory may change over time (Frankland et al. 2004; Maviel et al. 2004; Do-Monte et al. 2015). To test the stability of the circuitry necessary for changes from low to high generalization, we separated the first test and the second training session by $12 \mathrm{~d}$. At extended time points, we found that protein synthesisdependent plasticity in the $\mathrm{MgN}$ remains a critical factor for the increased fear to the CS-, suggesting a stable role for the $\mathrm{MgN}$ in shifts from low to high fear generalization. Our results are consistent with previous work showing overexpression of CREB in the $\mathrm{MgN}$ results in generalized fear to auditory cues following conditioning (Han et al. 2008) and that MgN plasticity is necessary for the induction of amygdala LTP, highlighting the importance of $\mathrm{MgN}$ plasticity for processes occurring within the amygdala (Apergis-Schoute et al. 2005). Therefore, it is likely that inhibition of $\mathrm{MgN}$ protein synthesis is disrupting plasticity necessary for the formation of both low and high generalized memories in the amygdala.

Next, we determined how MgN protein synthesis affects amygdala plasticity as a result of the second training session. We specifically focused on AMPA receptors in the amygdala because they are postsynaptic to thalamic terminals and are altered in expression at synapses following fear conditioning, providing potential end point to detect the effects of MgN activity on memory formation (Farb and LeDoux 1997; Yeh et al. 2006; Radley et al. 2007). After the second training session, we found increased GluR1 and SHANK protein in synaptic fractions. Interestingly, PKA activity drives GluR1 containing subunits into the synapse (Banke et al. 2000; Zheng and Keifer 2009) and facilitation of PKA activity in the amygdala is sufficient to drive generalization of fear, supporting a link between GluR1 and the formation of a generalized fear memory (Ghosh and Chattarji 2015). Attenuating generalization with $\mathrm{MgN}$ protein synthesis inhibition reduced GluR1 and SHANK levels to baseline. Previous work has shown that auditory cortex inactivation prior to a similar training session using an elevated shock intensity was not able to prevent the increase in CS- freezing, suggesting that $\mathrm{MgN}$ but not auditory cortex activity is critical for the shift in CS- responding as a result of elevated shock intensity (Ghosh and Chattarji 2015). It is important to note that the auditory stimuli used during training were simple pure tones and may not have evoked sufficient auditory cortex activity necessary to identify a role during auditory fear generalization.

We were also interested in the number of synaptic connections changing as a factor of retraining. Levels of PSD95 and synaptophysin may reflect synapse stability and functionality, which change in response to learning and memory updating (Ehrlich et al. 2007; Elkobi et al. 2008; Fitzgerald et al. 2015; Guan et al. 2009). Interestingly, there were no changes in PSD95 or synaptophysin following increased training suggesting there were changes in the stability of existing synaptic connections. Based on this, the second training session that resulted in elevated CS- freezing was likely supported by changes in expression of AMPA receptors at synaptic connections modified after the initial discrimination training session. The second training session may have modified the original fear memory through memory updating mechanisms. While our results are consistent with a role for the MgN in transitions from low to high states of fear generalization, the $\mathrm{MgN}$ may 
have a larger role in modification of amygdala-dependent fear memories that is not limited to fear generalization. Our results show that the increases in fear to safety cues as a result of the additional training session may be due to the increases in amygdala GluR1 and SHANK synaptic expression.

\section{Conclusion}

We provide data showing $\mathrm{MgN}$ protein synthesis-dependent plasticity that contributes to auditory fear discrimination and modulates amygdala encoding of fear memories during changes from low to high fear generalization. Specifically, MgN protein synthesis-dependent plasticity during learning is critical for changes in fear expression from low-to-high generalization, and prevents changes in amygdala synaptic expression of AMPA receptors and synapse stability without requiring new synaptic connections. These results provide a mechanism of presynaptic plasticity that may be contributing to elevated amygdala excitability underlying generalization of fear.

\section{Materials and Methods}

\section{Subjects}

Subjects were male Long Evans rats from Envigo ( $n=90$; Madison, WI) weighing $\sim 350 \mathrm{~g}$ at the time of arrival. Rats were individually housed with free access to water and rat chow. The animal colony was maintained at a 14:10-h light-dark cycle with all experiments occurring under the light portion of the cycle. All experiments were approved by the Institutional Animal Care and Use Committee.

\section{Surgery}

Immediately before surgery, rats were anesthetized with $4 \%$ isoflurane and oxygen, and after induction, isoflurane levels were maintained at $2 \%-2.5 \%$ throughout the surgery. Animals were implanted with bilateral cannulae targeting the $\mathrm{MgN}(-5.3 \mathrm{~mm}$ posterior, $\pm 2.8 \mathrm{~mm}$ lateral, $-5.6 \mathrm{~mm}$ ventral) relative to bregma (Paxinos and Watson 2007). Each cannula was secured to the skull with a screw and surrounded by acrylic cement. An obturator was screwed into the guide cannula to prevent occlusion. Rats were given a minimum of $7 \mathrm{~d}$ after surgery to recover before behavioral training and testing.

\section{Apparatus}

Auditory fear conditioning was conducted in a set of four Plexiglas and stainless steel chambers within sound-attenuating boxes (Context A). The floor included 18 stainless steel bars connected to a shock generator (Coulbourn Instruments). Each chamber had a speaker to allow delivery of pure tones, overhead illumination with a $7.5 \mathrm{~W}$ bulb, and ventilation fans to provide a constant background noise $(55 \mathrm{~dB})$. The chambers were cleaned with $5 \%$ ammonium hydroxide solution between sets of rats. A set of similar chambers designated Context B served as a shifted context for auditory CS testing. Context B had several distinct features including textured Plexiglas flooring, infrared illumination, and 5\% acetic acid cleaning solution.

\section{Drug preparation and infusion}

Animals were adapted to transport handling procedures for $3 \mathrm{~d}$ before conditioning, which included a gentle restraint during the sound of the infusion pump. Drugs were prepared on the day of infusion. Thirty minutes before conditioning, rats received bilateral microinjections of anisomycin $(125 \mu \mathrm{g} / \mu \mathrm{L}$, Tocris), or vehicle (ACSF) at a rate of $0.5 \mu \mathrm{L} / \mathrm{min}$ and at a volume of $0.5 \mu \mathrm{L} / \mathrm{hemi}$ sphere based on the effectiveness in prior studies (Parsons et al. 2006a; Kwapis et al. 2011). Anisomycin was dissolved in $\mathrm{HCl}$ and diluted with artificial CSF. Drugs were infused through 33-ga injection cannulae extending $0.5-0.7 \mathrm{~mm}$ beyond the guide cannulae. Injectors remained in place for $90 \mathrm{sec}$ following infusion to ensure drug diffusion. Rats were returned to their home cages after injections.

\section{Behavioral procedures}

Rats were placed in Context A for differential fear conditioning. During the first training session, rats received 10 counterbalanced CS+ and CS- presentations. CS+ cues were always paired with a shock (1 sec, $0.5 \mathrm{~mA})$, and CS- cues were never paired with shock. The average intertrial interval between each tone presentation was $70 \mathrm{sec}$. Tone duration was $10 \mathrm{sec}$ with a frequency of either $1 \mathrm{kHz}$ $(65 \mathrm{~dB})$ or $7 \mathrm{kHz}(55 \mathrm{~dB})$ and frequencies were counterbalanced between groups. During the second training session, rats received the identical training procedure at an elevated shock intensity (1 sec, $1.0 \mathrm{~mA}$ ). Groups that received two training sessions were infused with vehicle prior to the first training session, then animals were divided into groups based on level of discrimination on day 2 before receiving anisomycin or vehicle infusions prior to the second training session.

Auditory CS testing took place in Context B $24 \mathrm{~h}$ after conditioning. Rats received five discrete tone presentations of the CSthen five of the CS+ (30 sec; $60 \mathrm{sec}$ ITI) following a $60 \mathrm{sec}$ stimulus free period. Freezing was defined as the cessation of all movement excluding respiration and was automatically scored in real-time with FreezeScan 1.0 detection software (Clever Sys, Inc.) calibrated to a trained human observer.

\section{Synaptosomal membrane preparation}

Animals were deeply anesthetized with isoflurane 30 or $90 \mathrm{~min}$ following training. Brains were immediately removed, flash frozen with dry ice, and stored at $-80^{\circ} \mathrm{C}$ until dissected. Crude synaptosomal fractions were obtained as previously described (Jarome et al. 2011). Amygdalae were dissected out and homogenized in TEVP buffer with $320 \mathrm{mM}$ sucrose and were then centrifuged at $1000 \mathrm{~g}$ for $10 \mathrm{~min}$. The supernatant was removed and centrifuged at $10,000 \mathrm{~g}$ for $10 \mathrm{~min}$, and the remaining pellet was denatured in lysis buffer (all in $100 \mathrm{~mL} \mathrm{DDH}_{2} \mathrm{O} ; 0.605 \mathrm{~g}$ Tris- $\mathrm{HCl}, 0.25 \mathrm{~g}$ sodium deoxycholate, $0.876 \mathrm{~g} \mathrm{NaCl}, 1 \mu \mathrm{g} / \mathrm{mL}$ PMSF, $1 \mu \mathrm{g} / \mathrm{mL}$ leupeptin, 1 $\mu \mathrm{g} / \mathrm{mL}$ aprotinin, $10 \mathrm{~mL} 10 \%$ SDS). Protein levels were measured with a protein assay kit (Bio-Rad Laboratories).

\section{Western blot method}

Groups were trained as described above and sacrificed at 30- or 90-min post-conditioning. Following synaptosomal preparation, protein levels were normalized and loaded onto an SDS/PAGE gel and then to a membrane using a transfer apparatus (Bio-Rad). Membranes were incubated in blocking buffer for $1 \mathrm{~h}$ before being incubated in GluR1 (Cell Signaling, 1:1000), GluR2 (Santa Cruz, 1:500), SHANK (StressMarq, 1:1000), PSD95 (1:1000, Santa Cruz), synaptophysin (1:1000, Santa Cruz), or actin (Cell Signaling, $1: 1000)$ primary solutions overnight at $4^{\circ} \mathrm{C}$. Membranes were then incubated in the appropriate secondary antibody for $1 \mathrm{~h}$ and prepped in a chemiluminescence solution for $3 \mathrm{~min}$. Images were captured and densitometry performed using NIH Genesys.

\section{Statistical analyses}

All statistical analyses and graphing were conducted in Prism 7 software (Graphpad) software. Western blot samples normalized to actin levels are expressed as a percentage of control groups that did not receive a second training session. Behavioral and Western blot statistical outliers were defined as being two standard deviations above or below group mean and were excluded from all subsequent analyses. The data presented in this paper excludes one outlier from Figure 1 in the vehicle condition, one anisomycin and one vehicle group outlier for recent and remote time points in Figure 2, and a 90-min and no reactivation outlier in the 
vehicle condition in Figure 3. The data are presented as group averages with standard error of the mean (SEM). CS change scores were calculated by averaging ratios of CS+ and CS- presentations on the test day 1 and test day 2 for each animal to measure individual differences in freezing between test days. SEM is presented as the standard deviation of all ratios and divided by the number of subjects in each group. Western blot samples were analyzed using a one-way analysis of variance (ANOVA) and behavior groups were analyzed using a two-way repeated-measures ANOVA. Fisher least significant difference (LSD) post hoc tests were used when appropriate.

\section{Acknowledgments}

This work was supported by National Institutes of Health (NIH) grants MH069558 and MH112141 (F.J.H.).

\section{References}

Antunes R, Moita M. 2010. Discriminative auditory fear learning requires both tuned and nontuned auditory pathways to the amygdala. J Neurosci 30: $9782-9787$.

Apergis-Schoute AM, Debiec J, Doyère V, LeDoux JE, Schafe GE. 2005. Auditory fear conditioning and long-term potentiation in the lateral amygdala require ERK/MAP kinase signaling in the auditory thalamus: a role for presynaptic plasticity in the fear system. J Neurosci 25: 5730-5739.

Banke TG, Bowie D, Lee HK, Huganir RL, Schousboe A, Traynelis SF. 2000. Control of GluR1 AMPA receptor function by cAMP-dependent protein kinase. I Neurosci 20: 89-102.

Bergado-Acosta JR, Sangha S, Narayanan RT, Obata K, Pape HC, Stork O. 2008. Critical role of the $65-\mathrm{kDa}$ isoform of glutamic acid decarboxylase in consolidation and generalization of Pavlovian fear memory. Learn Mem 15: 163-171.

Cullen PK, Gilman TL, Winiecki P, Riccio DC, Jasnow AM. 2015. Activity of the anterior cingulate cortex and ventral hippocampus underlie increases in contextual fear generalization. Neurobiol Learn Mem 124: 19-27.

Do-Monte FH, Quiñones-Laracuente K, Quirk GJ. 2015. A temporal shift in the circuits mediating retrieval of fear memory. Nature 519: 460-463.

Ehrlich I, Klein M, Rumpel S, Manilow R. 2007. PSD-95 is required for activity-driven synapse stabilization. Proc Natl Acad Sci 104: 4176-4181.

Elkobi A, Ehrlich I, Beleovsky K, Barki-Harrington L, Rosenblum K. 2008. ERK-dependent PSD-95 induction in the gustatory cortex is necessary for taste learning, but not retrieval. Nat Neurosci 11: 1149-1151.

Farb CR, LeDoux JE. 1997. NMDA and AMPA receptors in the lateral nucleus of the amygdala are postsynaptic to auditory thalamic afferents. Synapse 27: 106-121.

Fitzgerald PJ, Pinard CR, Camp MC, Feyder M, Sah A, Bergstrom HC, Graybeal C, Liu Y, Schlüter OM, Grant SG, et al. 2015. Durable fear memories require PSD-95. Mol Psychiatry 20: 901-912.

Frankland PW, Bontempi B, Talton LE, Kaczmarek L, Silva AJ. 2004. The involvement of the anterior cingulate cortex in remote contextual fear memory. Science 304: 881-883.

Gafford GM, Parsons RG, Helmstetter FJ. 2013. Memory accuracy predicts hippocampal mTOR pathway activation following retrieval of contextual fear memory. Hippocampus 23: 842-847.

Gale GD, Anagnostaras SG, Godsil BP, Mitchell S, Nozawa T, Sage JR, Wiltgen B, Fanselow FS. 2004. Role of the basolateral amygdala in the storage of fear memories across the adult lifetime of rats. J Neurosci 24: 3810-3815.

Ghosh S, Chattarji S. 2015. Neuronal encoding of the switch from specific to generalized fear. Nat Neurosci 18: 112-120.

Goosens KA, Hobin JA, Maren S. 2003. Auditory-evoked spike firing in the lateral amygdala and Pavlovian fear conditioning: mnemonic code or fear bias? Neuron 40: 1013-1022.

Groves PM, Thompson RF. 1970. Habituation: a dual-process theory. Psychol Rev 77: 419-450.

Guan J, Haggarty SJ, Giacometti E, Dannenberg J, Joseph N, Gao J, Nieland TJF, Zhou Y, Wang X, Mazitschek R, et al. 2009. HDAC2 negatively regulates memory formation and synaptic plasticity. Nature 459: 55-60.

Han J, Yiu A, Cole C, Hsiang H, Neve R, Josselyn S. 2008. Increasing CREB in the auditory thalamus enhances memory and generalization of auditory conditioned fear. Learn Mem 15: 443-453.
Helmstetter FJ, Parsons RG, Gafford GM. 2008. Macromolecular synthesis, distributed synaptic plasticity, and fear conditioning. Neurobiol Learn Mem 89: 324-337.

Humeau Y, Reisel D, Johnson AW, Borchardt T, Jensen V, Gebhardt C, Bosch V, Gass P, Bannerman DM, Good MA, et al. 2007. A pathway-specific function for different AMPA receptor subunits in amygdala long-term potentiation and fear conditioning. J Neurosci 27: 10947-10956.

Jarome TJ, Werner CT, Kwapis JL, Helmstetter FJ. 2011. Activity dependent protein degradation is critical for the formation and stability of fear memory in the amygdala. PLOS ONE 6: e24349.

Jovanovic T, Ressler KJ. 2010. How the neurocircuitry and genetics of fear inhibition may inform our understanding of PTSD. Am J Psychiatry 167: 648-662.

Jovanovic T, Norrholm SD, Blanding NQ, Davis M, Duncan E, Bradley B, Ressler KJ. 2010. Impaired fear inhibition is a biomarker of PTSD but not depression. Depress Anxiety 27: 244-251.

Jovanovic T, Kazama A, Bachevalier J, Davis M. 2012. Impaired safety signal learning may be a biomarker of PTSD. Neuropharmacology 62: 695-704.

Kraus M, Schicknick H, Wetzel W, Ohl F, Staak S, Tischmeyer W. 2002. Memory consolidation for the discrimination of frequency-modulated tones in Mongolian gerbils is sensitive to protein synthesis inhibitors applied to the auditory cortex. Learn Mem 9: 239-303.

Kwapis JL, Jarome TJ, Schiff JC, Helmstetter FJ. 2011. Memory consolidation in both trace and delay fear conditioning is disrupted by intra-amygdala infusion of the protein synthesis inhibitor anisomycin. Learn Mem 18: 728-732.

Kwon J, Nakajima R, Kim H, Jeong Y, Augustine G, Han J. 2014. Optogenetic activation of presynaptic inputs in lateral amygdala forms associative fear memory. Learn Mem 21: 627-633.

Likhtik E, Stujenske JM, Topiwala MA, Harris AZ, Gordon JA. 2014. Prefrontal entrainment of amygdala activity signals safety in learned fear and innate anxiety. Nat Neurosci 17: 106-113.

Maren S, Ferrario CR, Corcoran KA, Desmond TJ, Frey KA. 2003. Protein synthesis in the amygdala, but not the auditory thalamus, is required for consolidation of Pavlovian fear conditioning in rats. EurJ Neurosci 18: 3080-3088.

Maviel T, Durkin TP, Menzaghi F, Bontempi B. 2004. Sites of neocortical reorganization critical for remote spatial memory. Science 305: $96-99$.

Migues PV, Hardt O, Wu DC, Gamache K, Sactor TC, Wang YT, Nader K. 2010. PKM $\zeta$ maintains memories by regulating GluR2-dependent AMPA receptor trafficking. Nat Neurosci 13: 630-634.

Norrholm SD, Jovanovic T, Olin IW, Sands LA, Karapanou I, Bradley B, Ressler KJ. 2011. Fear extinction in traumatized civilians with posttraumatic stress disorder: relation to symptom severity. Biol Psychiatry 69: 556-563.

Parsons RG, Riedner BA, Gafford GM, Helmstetter FJ. 2006a. The formation of auditory fear memory requires the synthesis of protein and mRNA in the auditory thalamus. Neuroscience 141: 1163-1170.

Parsons RG, Gafford GM, Baruch DE, Riedner BA, Helmstetter FJ. 2006b. Long-term stability of fear memory depends on the synthesis of protein but not mRNA in the amygdala. EurJ Neurosci 23: 1853-1859.

Paxinos G, Watson C. 2007. The rat brain in stereotaxic coordinates. Academic, Amsterdam, The Netherlands.

Pedroso TR, Jobim PFC, Carvalho LM, Christoff RR, Maurmann N, Reolon GK, Werenicz A, Roesler R. 2013. Inhibition of protein synthesis or mTOR in the basolateral amygdala blocks retrieval-induced memory strengthening. J Neural Transm (Vienna) 120: 1525-1531.

Radley JJ, Farb C, He Y, Janssen WGM, Rodrigues SM, Johnso LR, Hof PR, LeDoux JE, Morrison JH. 2007. The distribution of NMDA and AMPA receptor subunits at thalamo-amygdala dendritic spines. Brain Res 1134: 87-94.

Sanford CA, Soden ME, Baird MA, Miller SM, Schulkin J, Palmiter RD, Clark M, Zweifel LS. 2017. A central amygdala CRF circuit facilitates learning about weak threats. Neuron 93: 164-178.

Schmitt WB, Deacon RM, Seeburg PH, Rawlins JN, Bannerman DM. 2003. A within-subjects, within-task demonstration of intact spatial reference memory and impaired spatial working memory in glutamate receptor-A-deficient mice. J Neurosci 23: 3953-3959.

Shaban H, Humeau Y, Herry C, Cassasus G, Shigemoto R, Ciocchi S, Barbieri S, van der Putten H, Kaupmann K, Bettler B, et al. 2006. Generalization of amygdala LTP and conditioned fear in the absence of presynaptic inhibition. Nature Neurosci 9: 1028-1035.

Thoeringer CK, Henes K, Eder M, Dahlhoff M, Wurst W, Holsboer F, Deussing JM, Moosmang S, Wotjak C. 2012. Consolidation of remote fear memories involves corticotropin-releasing hormone (CRH) 
receptor type 1-mediated enhancement of AMPA receptor GluR1 signaling in the dentate gyrus. Neuropsychopharmacology 37: 787-796.

Tronson NC, Wiseman SL, Olausson P, Taylor JR. 2006. Bidirectional behavioral plasticity of memory reconsolidation depends on amygdalar protein kinase A. Nat Neurosci 9: 167-169.

Vanvossen AC, Portes MAM, Scoz-Silva R, Reichmann HB, Stern CAJ, Bertoglio LJ. 2017. Newly acquired and reactivated contextual

fear memories are more intense and prone to generalize after activation of prelimbic cortex NMDA receptors. Neurobiol Learn Mem 137: $154-162$.
Xu W, Südhof TC. 2013. A neural circuit for memory specificity and generalization. Science 339: 1290-1295.

Yeh S, Mao S, Lin H, Gean P. 2006. Synaptic expression of glutamate receptor after encoding of fear memory in the rat amygdala. $\mathrm{Mol}$ Pharmacol 69: 299-308.

Zheng Z, Keifer J. 2009. PKA has a critical role in synaptic delivery of GluR1and GluR4-containing AMPARs during initial stages of acquisition of in vitro classical conditioning. J Neurophysiol 101: 2539-2549.

Received April 6, 2017; accepted in revised form July 5, 2017. 


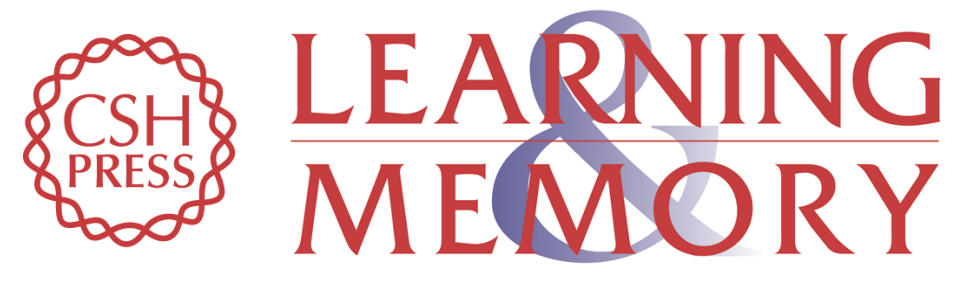

\section{Input from the medial geniculate nucleus modulates amygdala encoding of fear memory discrimination}

Nicole C. Ferrara, Patrick K. Cullen, Shane P. Pullins, et al.

Learn. Mem. 2017, 24:

Access the most recent version at doi:10.1101/Im.044131.116

\begin{aligned} & \hline References $\begin{array}{l}\text { This article cites } 45 \text { articles, } 15 \text { of which can be accessed free at: } \\ \text { http://learnmem.cshlp.org/content/24/9/414.full.html\#ref-list-1 }\end{array} \\ & \begin{array}{r}\text { Creative } \\ \text { Commons } \\ \text { License }\end{array} \begin{array}{l}\text { This article is distributed exclusively by Cold Spring Harbor Laboratory Press for the } \\ \text { first } 12 \text { months after the full-issue publication date (see } \\ \text { http://learnmem.cshlp.org/site/misc/terms.xhtml). After } 12 \text { months, it is available under } \\ \text { a Creative Commons License (Attribution-NonCommercial } 4.0 \text { International), as } \\ \text { described at http://creativecommons.org/licenses/by-nc/4.0/. }\end{array} \\ & \begin{array}{c}\text { Receive free email alerts when new articles cite this article - sign up in the box at the } \\ \text { top right corner of the article or click here. }\end{array} \\ & \begin{array}{c}\text { Service } \\ \text { terting }\end{array}\end{aligned}$ 